\title{
Deep-hole rupture controlled blasting of complicated high slope
}

\author{
H B Wang \& Q Zong
}

\author{
School of Civil Engineering and Architecture , Anhui University of Science and Technology , \\ Huainan , Anhui 232001
}

KEYWORD: complicated condition; high slope; rupture blasting; blasting parameters ABSTRACT: In order to avoid the negative impact of field flat blasting on the surrounding buildings and foundation pit, using deep-hole rupture control scheme. Design of blast hole orifice spacing is $3.0 \mathrm{~m}$, row spacing is $2.5 \mathrm{~m}$; diameter of hole is $90 \mathrm{~mm}$, hole depth between $11 \mathrm{~m}$ to $12.6 \mathrm{~m}$; adopt rock emulsion explosive with diameter $70 \mathrm{~mm}, 500 \mathrm{~mm}$ long; plastic detonating tube detonators is used for blasting hole by hole. Sand bag is placed in hole orifice for prevent punching and flying rock. Layout blasting vibration observation points around buildings for blasting vibration monitoring. Blasting and monitoring results show that the design of blasting parameters, detonating network of hole by hole and protective measures control the blasting vibration and flying rock effectively, good blasting results is achieved.

\section{GENERAL SITUATION OF THE PROJECT}

Due to long-term exploitation of stone in the mountain, a new community district of Huainan in China surface damaged seriously. The scope of architectural planning have a trapezoidal rock slope towards in the west to the east, mainly rock is composed of bedded limestone, the slope contain $50 \mathrm{~m}$ in the construction scope, with width $20 \mathrm{~m}$ in top, and $25 \mathrm{~m}$ in bottom. The surface of slope is lower in center region and higher in board regions, difference of elevation from 0 to $1.2 \mathrm{~m}$, the top of slope is about $5 \mathrm{~m}$ above the surface in south, and about $10 \mathrm{~m}$ above the surface in north. The design for residential building include 16 layers on the ground and one layer under the ground, the design elevation in floors of basement is $1.6 \mathrm{~m}$ under the ground ( in north side ), and max height of blasting is $11.6 \mathrm{~m}$.

The environment of blasting site is complex, a new foundation is located in the eastern side, and concrete has been poured, from the bottom of slope to foundation is recently $1.0 \mathrm{~m}$. Southeast of the site is the enclosing wall, outside the wall is a six layers residential buildings, vertical distance to the slope is $12.8 \mathrm{~m}$. A new frame building in the southern, has been constructed to four layers, distance to the slope is $1.0 \mathrm{~m}$ in bottom. The building in the north has been completed; distant to the slope is $85 \mathrm{~m}$. Hillside in western, surrounding environment shown in Figure1 and Figure 2.

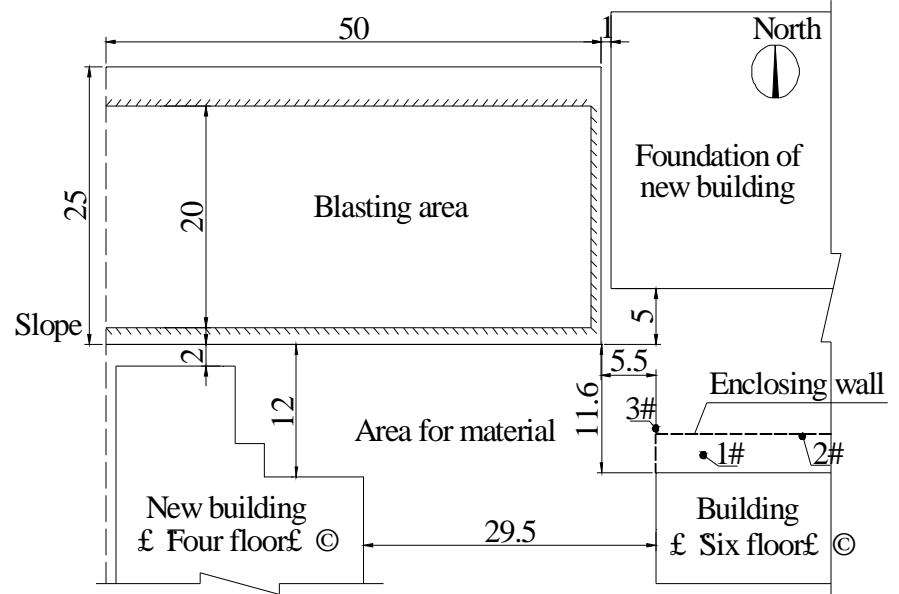

Figure1 Surrounding environment of blasting field ( Unit: $\mathrm{m}$ ) 


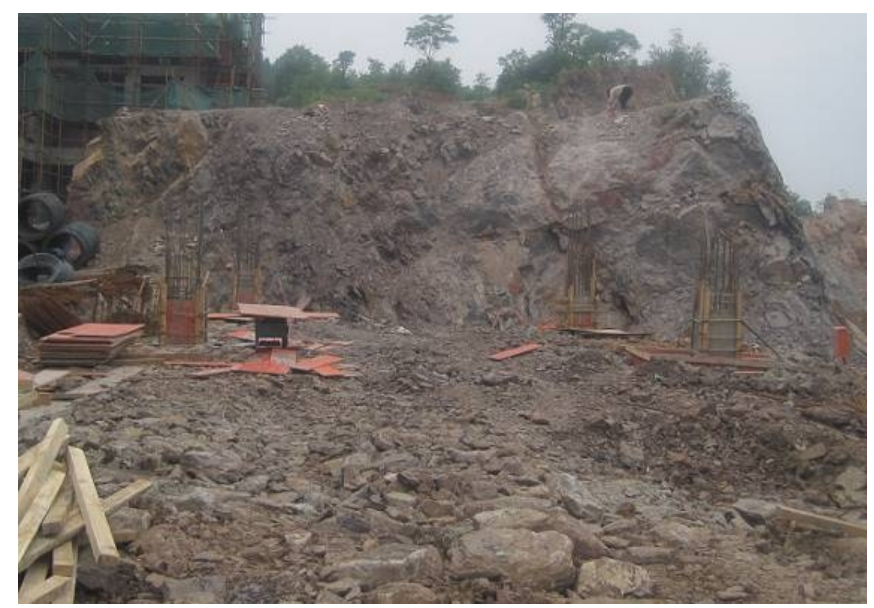

(a) The east side

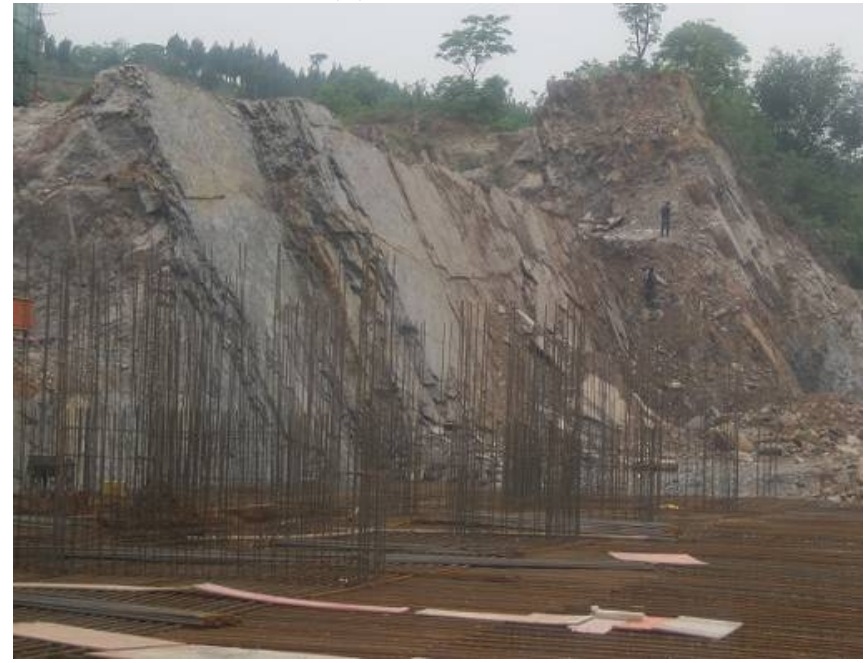

(b) The north side

Figure2 Elevation of blasting field before blasting

\section{DIFFICULTIES OF THE PROJECT}

( 1 ) Complex environment and high requirements of blasting safety

The slope is close to buildings, with distances from the nearest construction only $2.0 \mathrm{~m}$, and from one habitant house only $12.8 \mathrm{~m}$, blasting operation can not effect the construction of new buildings, blasting safety requirements are high, adverse effects caused by blasting vibration and flying stone on surrounding buildings must be controlled.

( 2 ) Slope size is large, protection is difficult

There are buildings, building construction site, steel, templates and other materials covered on the floor nearby the blasting area; at the same time, the blasting area is larger(long $50 \mathrm{~m}$, bottom width $25 \mathrm{~m}$, maximum height $11.6 \mathrm{~m}$ ), it is difficult to take protection. Distance between blasting slope and new building is only $2.0 \mathrm{~m}$, if the rock mass collapse into the building after blasting will cause adverse impact on the structure, even have no negative effect, the artificial cleaning of rock and soil are not easy.

( 3 ) Drilling precision is hard to control for slope is up-narrow and down-wide

Cross-sectional of slope is trapezium ( narrow top and wide bottom ), when drilling on the upper surface, it is different to control rake angle and azimuth angle of the hole, especially for the building of south side, the deviation of hole rake angle will affect the distance of minimum resistance; rock and soil will thrown into building after blasting for small distance.

There are three difficulties for the complex environment, therefore, the blasting should only increases the crack development in slope and causes damage with no throwing, this can ensure the safety of surrounding buildings. 


\section{BLASTING SCHEME AND PARAMETER DESIGN}

\section{Blasting scheme}

In view of the complex environment, maximum height of blasting is $11.6 \mathrm{~m}$, if adopted the short-hole blasting, it not only extend the project time, but also can cause large quantity fly stone, it will affects residents living around and building engineering construction, and increases cost of protection, compensation and other related cost. Based on scheme comparison, deep-hole pre-splitting blasting is adopted, blasting to the design elevation one time, increasing the crack in rock mass, reducing it integrity, then using pick machine, milling machine and other machinery and equipment for secondary crushing ${ }^{[1]}$.

\section{Drilling equipment and blasting materials}

Blasting hole drilled by in-the-hole drill YQ100, blasting hole diameter is $90 \mathrm{~mm}$, explosive is rock emulsion explosive with diameter $70 \mathrm{~mm}$, each explosive length is $500 \mathrm{~mm}$, plastic detonating tube detonators is used for initiation.

\section{Blasting parameters}

( 1 ) Range and row distance

According to the causes and mechanism of open-pit bench blast seism, and considering the fly stone and air shock wave direction, the building in southern of blasting zone is the key object for protection, followed by completed foundation which is built in the east and north. The line of weakness direction is the north, protected object is located in the back and side of the line, it can not only reduce the impact of blast seism, but also reduce the harm to the building of the fly stone.

Due to using split blasting, a larger line of weakness should be selected. According to the diameter of blasting hole, line of weakness $W_{d}=(20 \sim 50) d$, the diameter of blasting hole is $90 \mathrm{~mm}$,

by calculation, takes $3.0 \mathrm{~m}$ as distance between hole and edge of slope in South, $1.5 \mathrm{~m}$ in North and $3.0 \mathrm{~m}$ for East. Distance between holes are $3.0 \mathrm{~m}$, row distance is $2.5 \mathrm{~m}$, the holes in a triangular arrangement

( 2 ) Hole depth $L$

According to the angel of the north and south sides of the slope, holes nearby the south as vertical hole, and inclined hole for north side, rake angle from $75^{\circ}$ to $80^{\circ}$, extra-deep is $1.0 \mathrm{~m}$, the actual blasting hole depth is determined by the ground relief, and the hole layout and the rake angle are shown in Figure2.

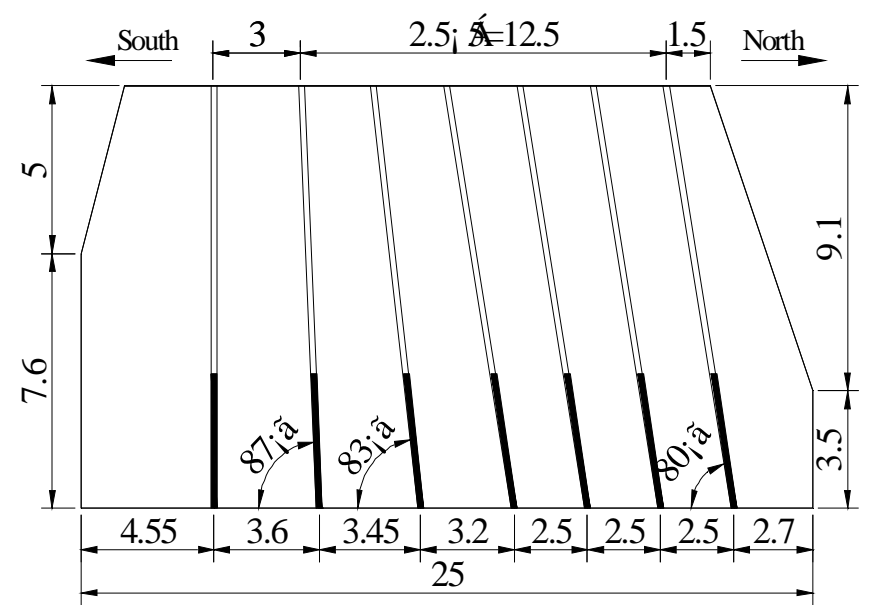

Figure2 Schematic diagram of hole parameter and charge structure ( Unit: $\mathrm{m}$ )

( 3 ) Consumption of explosives $q$ and single hole charge $Q$

For controlling the blast vibration and fly stone, and combined with the actual situation of rock, the charge of single hole calculated by formula as follow ${ }^{[2]}$ :

$Q=q a b H$ 
Where: $q$ is explosive consumption of unit volume rock blasting, $0.4 \mathrm{~kg} / \mathrm{m}^{3} ; a$ is distance between holes, $3.0 \mathrm{~m}$; $b$ is row spacing, selected according to Figure $2 ; H$ is hole depth, from 11 to $12.6 \mathrm{~m}$.

Calculated explosive consumption of different depth: charge $37.1 \mathrm{~kg}$ for hole depth $11 \mathrm{~m}$; charge $40.5 \mathrm{~kg}$ for hole depth $12 \mathrm{~m}$ and charge $42.5 \mathrm{~kg}$ for hole depth $12.6 \mathrm{~m}$.

( 4 ) Stemming of blasting hole

All holes used rock powder and clay soil to clog full depth after charging, and with sandbags to prevent hole punching press.

( 5 ) Blasting network

In order to reduce the influence of blast vibration on the surrounding environment, plastic blast pipe network is adopted. which use a detonator that delay time is $50 \mathrm{~ms}$ in hole, and delay time $25 \mathrm{~ms}$ between holes in one row, and $110 \mathrm{~ms}$ between rows ${ }^{[3 \sim 5]}$.

\section{SAFETY CONTROL TECHNOLOGY OF BLASTING}

Adverse effects of blasting main contain blast vibration, noise, fly stone and harmful gases ${ }^{[2]}$, in the engineering, noise and harmful gas will not produce adverse effects, controlling on the blast vibration and fly stone is needed.

\section{Blast vibration}

Before blasting, the vibration monitoring points are arranged in the front of the buildings, the specific location is 1\#, 2\# and 3\# in Figure1. Instrument using the type of NUBOX-6016 vibration monitor, Figure 3 shows the curves of vibration velocity measured at the point of $1 \#$, it can be clearly seen that the blasting process is composed of different delay time, the duration of the whole blasting vibration is $2 \mathrm{~s}$, and the maximum peak velocity is less than $10 \mathrm{~mm} / \mathrm{s}$. According to Blasting Safety Regulation ${ }^{[6]}$, the blasting will not cause damage to the surrounding frame structures.
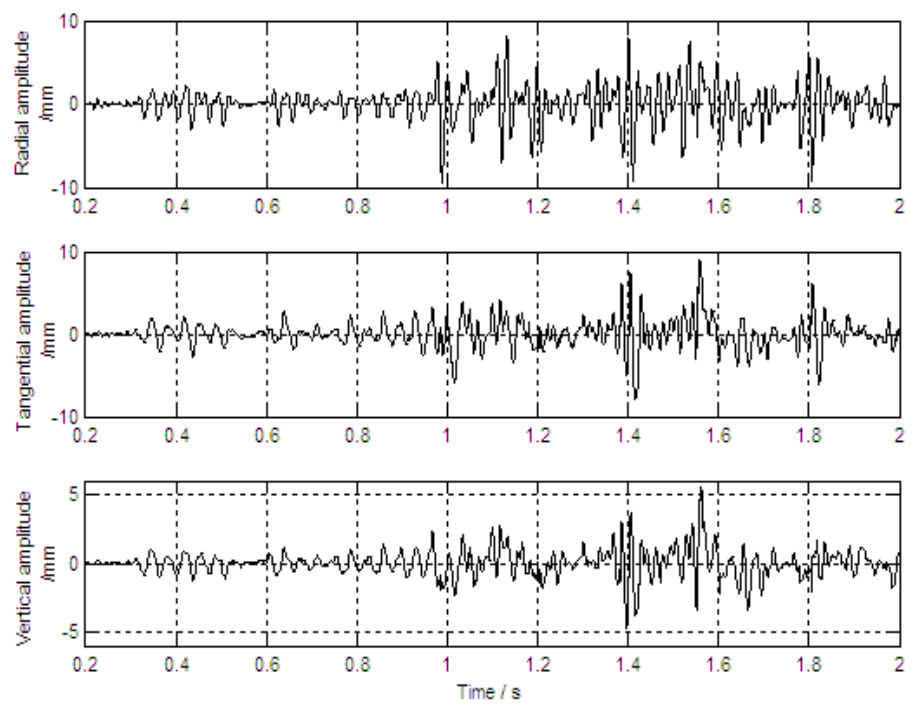

Figure 3 The vibration waveforms of $1 \#$ monitor field

\section{Controlling of fly stone}

Blasting fragments and a few scattered substances probably cause damage to the windows glass in surrounding buildings, overhead pipelines, etc. Rock powder and clay soil is used for holes clogging after charge, and with sandbags to prevent hole punching press.

\section{CONCLUSION}

For rock blasting engineering under complex environment, controlling the drilling quality strictly and blast one time, avoid multiple blasting, this resulting in "nuisance" and "residents interference".

The direction of blasting effect (line of weakness) must be optimized, line of weakness direction should avoid the buildings and facilities which need protected, it can not only reduce the influence of seismic wave effectively, and can also reduce the fly stone and adverse effects of shock wave on the 
building. The large distance should be reserved in the side of the building nearby blasting zone, which can cause damage to the building.

Millisecond blasting is adopted to control the explosive charge in single shot, so that the blasting seism wave energy is dispersed in time and space, which can effectively reduce the blast vibration.

Using millisecond blasting and hole by hole blasting technique make full use of the internal hole of explosive energy, which control of the damage of blast vibration and flying rocks effectively.

Using of decoupled charge structure and strengthening protection can control harmful effect.

\section{ACKNOWLEDGEMENTS}

This research was financially supported by the National Natural Science Foundation (Grant No.51404010, 51274009) and the Key Scientific and Technical Program of Anhui Province (Grant No. 1501041123). The authors are grateful to the reviews for their valuable comments.

\section{REFERENCES}

[1] Zhu Yipin, Chen Jianguo. Experience and Reflection on controlled blasting safety of city foundation pit [J]. Engineering blasting, 2014, 20 (2): 54-56.

[2] Wang Xuguang, Yu Yalu, Liu Dianzhong. Enforceable handbook of Blasting Safety Regulation[S]. Beijing: China Communications Press, 2004

[3] Wang Xiaofan. Comprehensive application of multiple controlled blasting technique under complicated condition [J]. Blasting, 2014, 31 (2): 149-152.

[4] Liao Kun, Long Yuan, Lv Haijun, et al. Blasting vibration monitoring of rock excavation in energy-saving technological transformation project of Nanjing steel group [J]. Blasting, 2013, 30 (2): 171-174.

[5] Chen Shaohui, Zhang Zhiyu, Xie Xianping, et al. Dynamic response and safety analysis of blasting vibration effects on high slope of Jinning phosphorus open-pit [J]. China safety science and technology, 2014, 10 (11): 41-47.

[6] National Standard of People's Republic of China, Blasting Safety Regulation (GB6722-2014) [S]. Beijing: China Standard Press, 2014. 